Article

\title{
Effect of TiB Orientation on Near-Threshold Fatigue Crack Propagation in TiB-Reinforced Ti-3Al-2.5V Matrix Composites Treated with Heat Extrusion
}

\author{
Shoichi Kikuchi ${ }^{1, *(\mathbb{D})}$, Shunsuke Tamai ${ }^{2}$, Takao Kawai ${ }^{2}$, Yoshikazu Nakai ${ }^{2}{ }^{(D}$, Hiroki Kurita ${ }^{3}(\mathbb{D}$ \\ and Sophie Gourdet ${ }^{4}$ \\ 1 Department of Mechanical Engineering, Faculty of Engineering, Shizuoka University, \\ Shizuoka 422-8017, Japan \\ 2 Department of Mechanical Engineering, Kobe University, Kobe, Hyogo 657-8501, Japan; \\ 1534552t@stu.kobe-u.ac.jp (S.T.); 171t318t@stu.kobe-u.ac.jp (T.K.); nakai@mech.kobe-u.ac.jp (Y.N.) \\ 3 Department of Materials Processing, Graduate School of Engineering, Tohoku University, Miyagi 980-8577, \\ Japan; kurita@material.tohoku.ac.jp \\ 4 Ariane Group, 78130 Les Mureaux, France; sophie.gourdet@ariane.group \\ * Correspondence: kikuchi.shoichi@shizuoka.ac.jp; Tel.: +81-53-478-1026
}

Received: 2 October 2019; Accepted: 7 November 2019; Published: 8 November 2019

\begin{abstract}
TiB-reinforced Ti-3Al-2.5V matrix composites, in which TiB whiskers are oriented parallel to the direction of heat extrusion, were fabricated via mechanical alloying and hot isostatic pressing (HIP). To investigate the near-threshold fatigue crack propagation in TiB-reinforced Ti-3Al-2.5V matrix composites, stress intensity factor $K$-decreasing tests were conducted for disk-shaped compact specimens having two different orientations of TiB whiskers at force ratios from 0.1 to 0.8 under ambient conditions. The crack growth rates, $\mathrm{d} a / \mathrm{d} N$, for the composites incorporating TiB whiskers oriented perpendicular to the direction of crack growth were constantly lower than those obtained in the case where the orientation was parallel at the same stress intensity range $\Delta K$, while the threshold stress intensity range, $\Delta K_{\text {th }}$, was higher. This effect can be explained by the increase in the degree of roughness-induced crack closure resulting from the perpendicular TiB, because fatigue cracks preferentially propagated across the boundaries between the matrix and the TiB in certain regions. In contrast, the effective threshold stress intensity range, $\Delta K_{\text {eff,th }}$, for composites was unaffected by the TiB orientation at low force ratios.
\end{abstract}

Keywords: fatigue; fracture mechanics; titanium alloy; titanium boride; crack closure

\section{Introduction}

As a result of their high heat resistance and superior specific strength, titanium alloys are frequently employed in aerospace components. Recently, there has been increasing interest in improving the structural reliability of such alloys by enhancing their mechanical properties, as a means of addressing the weight saving and downsizing for aerospace components. The microstructure of a metal typically determines its mechanical properties, and so modifying this microstructure could effectively improve the characteristics of materials based on titanium. Such modifications can be achieved using a variety of methods, including the generation of surface topography [1], the insertion of additional elements in an alloy [2-11], and grain refinement [11-14].

Prior work has demonstrated that the mechanical properties of stainless steels [15] and of alloys of magnesium [16], cobalt-chromium-molybdenum [17], and titanium [18-30] can all be improved via the addition of boron. The combination of titanium and boron generates whiskers of titanium boride ( $\mathrm{TiB})$ as a result of the reaction $\mathrm{Ti}+\mathrm{TiB}_{2} \rightarrow 2 \mathrm{TiB}$. Hyman et al. [31] and $\mathrm{Li}$ et al. [32] have 
reported that the growth of TiB occurred preferentially along the orthorhombic [010] direction during the sintering and hot isostatic pressing stages of composite fabrication. Feng et al. [33,34] characterized the microstructure of in situ synthesized $\mathrm{TiB}$ and interfacial structures, and clarified that the growth mechanism of TiB whiskers was a stacking process of the (100) plane of TiB. These whiskers exhibit chemical stability within the resulting alloys [25] because the coefficients of thermal expansion of pure titanium and of TiB are similar [26], such that residual thermal stress in the whiskers can be relieved within the alloy. Prior works $[19,27,28]$ have shown that TiB whiskers provide titanium alloys with improved tensile strength, and so the incorporation of $\mathrm{TiB}$ is a potential means of reinforcing titanium matrix composites (TMCs). Furthermore, Wang et al. [30] has reported that both the tensile strength and elongation of the TiB-reinforced Ti matrix composites were sharply increased after extrusion, which suggests that the orientation of TiB influences the mechanical properties of Ti matrix composites. Schuh et al. [35] has examined the behavior of TiB whisker alignment during uniaxial superplastic elongation of the Ti-6Al-4V reinforced with 10 vol.\% TiB whiskers.

The present work examined the fatigue resistance of titanium alloys reinforced with TiB treated with heat extrusion that show sufficient strength for practical engineering applications. The aim of this study was to establish the relationship between the orientation of TiB whiskers and crack propagation under near-threshold fatigue conditions in a Ti-3Al-2.5V alloy incorporating TiB. The mechanism by which fatigue cracks propagate through the alloy was also examined, based on fractography and the concept of crack closure.

\section{Experimental Procedures}

\subsection{Materials}

A powdered Ti-3Al-2.5V alloy (Crucible Materials Research, currently an Allegheny Technology, subsidiary, Pittsburgh, PA, USA,) having the composition provided in Table 1 was employed in this work. This material was generated by argon atomization and comprised spherical particles $58 \mu \mathrm{m}$ in diameter. $\mathrm{The}^{\mathrm{TiB}} \mathrm{B}_{2}$ was a ceramic powder with a particle diameter of $4.8 \mu \mathrm{m}$ and the composition provided in Table 2.

Table 1. Chemical composition of Ti-3Al-2.5V powder (mass $\%$ ).

\begin{tabular}{ccccccc}
\hline Al & $\mathbf{V}$ & $\mathbf{F e}$ & $\mathbf{C}$ & $\mathbf{O}$ & $\mathbf{N}$ & $\mathbf{T i}$ \\
\hline 3.28 & 2.48 & 0.04 & 0.069 & 0.122 & 0.008 & Bal. \\
\hline
\end{tabular}

Table 2. Chemical composition of $\mathrm{TiB}_{2}$ powder (mass $\%$ ).

\begin{tabular}{cccccc}
\hline B & Fe & C & O & $\mathbf{N}$ & Ti \\
\hline 30.0 & 0.1 & 0.5 & 1.1 & 0.6 & Bal. \\
\hline
\end{tabular}

The experimental composite was obtained by combining the Ti-3Al-2.5V with 6.4 vol\% $\mathrm{TiB}_{2}$, such that the mixture contained $10 \mathrm{vol} \%$ TiB. Details about the initial microstructure are described in the previous papers [36-38]. This was accomplished using a specialized high-energy mixing technique proprietary to Aerospace Metal Composites, termed mechanical alloying (MA). Following MA, the mixture was transferred into a steel container and degassed at $773 \mathrm{~K}$, after which the container was sealed airtight under vacuum. Finally, the powder was subjected to hot isostatic pressing (HIP) for $7.2 \mathrm{ks}$ at $1193 \mathrm{~K}$ in conjunction with a pressure of $140 \mathrm{MPa}$ to consolidate the material. After HIP, the composite was found to exhibit a heterogeneous microstructure in which the original Ti-3Al-2.5V grains were surrounded with $\mathrm{TiB} / \mathrm{TiB}_{2}$ at high concentrations. A portion of the $\mathrm{TiB}_{2}$ had transitioned to nano-sized needles of $\mathrm{TiB}$, while the remainder was present as large particles of $\mathrm{TiB}_{2}$ within zones in which TiB had been formed [36-38]. For this reason, additional heating for $14.4 \mathrm{ks}$ at $1473 \mathrm{~K}$ in a vacuum tube furnace was used to ensure the complete conversion of the original ceramic to TiB. 
Subsequent analysis demonstrated that the $\mathrm{TiB}_{2}$ particles were completely transformed to micro-sized needles of TiB following this second process [36-38]. The resulting composite was extruded at $1273 \mathrm{~K}$ while applying a force of $5 \mathrm{MN}$ using a press, in conjunction with a 15:1 extrusion ratio, so as to adjust the orientation of the TiB whiskers. The microstructure of the resulting composite over a region $40,000 \mu^{2}$ in size was characterized by electron probe micro analysis (EPMA) at 500× magnification, operating at a $15 \mathrm{kV}$ acceleration voltage. Furthermore, the microstructure of the composite was characterized using electron backscatter diffraction (EBSD) under the condition of $0.05 \mu \mathrm{m}$ in a step size at an accelerating voltage of $15 \mathrm{kV}$ to examine the crystal orientation of the TiB whisker.

\subsection{Experimental Tests}

Based on our prior work [39-45], a disk-shaped compact (DC(T)) sample type was employed in this work, similar to the specimen type referred to in the E399-17 ASTM standard. The composite was machined to produce specimens of this type having the sizes presented in Figure 1, after which the surfaces were polished to a mirror finish using emery papers (\#80-\#4000) followed by a suspension of $\mathrm{SiO}_{2}$.

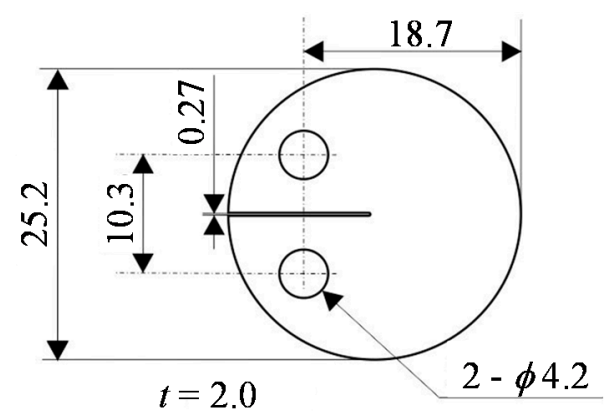

Figure 1. Specimen configuration for fatigue crack propagation tests.

Specimens having two different orientations of TiB whiskers were employed in the present research. Figure 2a provides a map of the TiB/Ti-3Al-2.5V alloy generated by EPMA showing the distribution of boron throughout the material. The positioning of the TiB could be adjusted by varying the direction of the heat extrusion process because the TiB whiskers were automatically oriented parallel to the direction of extrusion. Figure $2 b$ presents a schematic of two DC(T) specimens having different TiB orientations. These were obtained by machining of the bulk composite in the LT plane. In the case of the LT specimens, the TiB whiskers were aligned perpendicular to the crack growth direction, while the TL specimen had whiskers parallel to the crack growth direction. These samples were used to establish the relationship between the TiB orientation and the fatigue crack propagation in the TiB/Ti-3Al-2.5V alloy. Figure 3 shows inverse pole figure (IPF) maps obtained by EBSD analysis for the TiB-reinforced Ti-3Al-2.5V matrix composite at the SL plane. TiB had the same crystallographic orientation represented by blue colors in Figure 3c, and the (010) plane of TiB was perpendicular to the direction of heat extrusion.

An electrodynamic fatigue test apparatus with the loading capacity of $350 \mathrm{~N}$ for $\mathrm{DC}(\mathrm{T})$ specimens was used to examine the propagation of fatigue cracks in these specimens, employing three force ratios, $R$, ranging from 0.1 to 0.8 . Tests in which the stress intensity factor, $K$, was decreased, were performed in conjunction with a constant $R$ value to investigate the fatigue threshold for each sample. In each trial, the specimen was initially pre-cracked to a minimum distance of $1 \mathrm{~mm}$ relative to the notch tip, after which stress cycling was carried out at a frequency of $30 \mathrm{~Hz}$ under ambient conditions. The threshold stress intensity range, $\Delta K_{\text {th }}$, was taken to equal the largest range of stress intensity values obtained at a crack growth rate of $10^{-11} \mathrm{~m} /$ cycle. The unloading elastic compliance technique was used to determine the crack lengths [46]. The extent of crack closure was also estimated by obtaining the closure stress intensity factor, $K_{\mathrm{cl}}$, from the closure load, $P_{\mathrm{cl}}$. These data were used to find the effective stress intensity range, $\Delta K_{\text {eff }}$, calculated as $K_{\max }-K_{\mathrm{cl}}$, where the former term represents the maximum 
stress intensity factor $\left(\mathrm{MPa} \cdot \mathrm{m}^{1 / 2}\right)$. Values for $K$ were determined using the procedure provided in the E399-17 ASTM standard. The correlation between the backface compliance of the DC(T) specimens and the crack length can be summarized using Equations (1) and (2):

$$
\begin{gathered}
a / W=1-2.258 C_{\mathrm{n}}+0.9048 C_{\mathrm{n}}^{2} \\
C_{\mathrm{n}}=1 /\left[(E C B W)^{1 / 2}+1\right]
\end{gathered}
$$

where $a$ represents the length of the crack $(\mathrm{m}), W$ is the width of the specimen $(\mathrm{m}), E$ is the Young's modulus for the sample (GPa), $C$ is the compliance, and $B$ is the thickness of the specimen (m). Following the crack propagation trials, the crack profiles and fracture surfaces were observed by scanning electron microscopy (SEM).

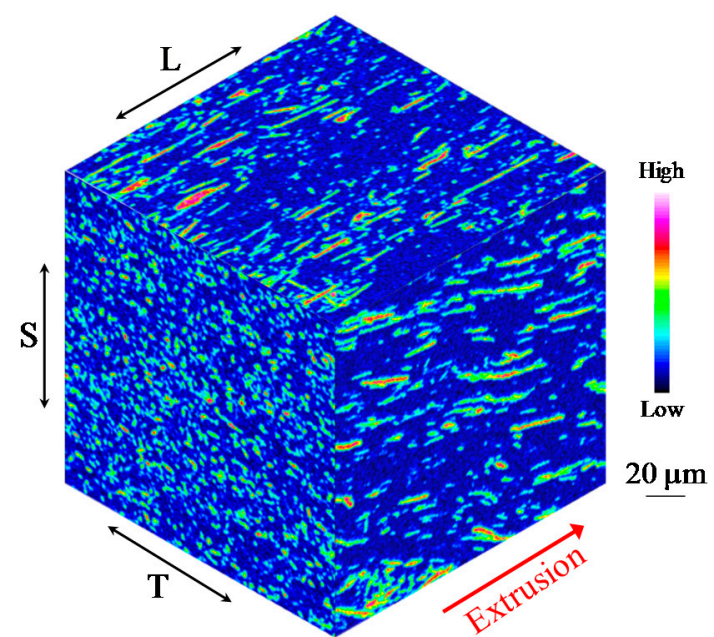

(a)

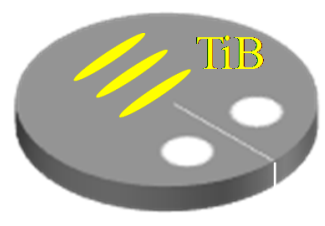

LT specimen

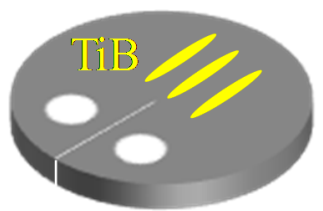

TL specimen

(b)

Figure 2. (a) Boron map obtained by electron probe micro analysis (EPMA) analysis for TiB/Ti-3Al-2.5V alloy; (b) Schematic illustration for the disk-shaped compact (DC(T)) specimens having different TiB orientations.
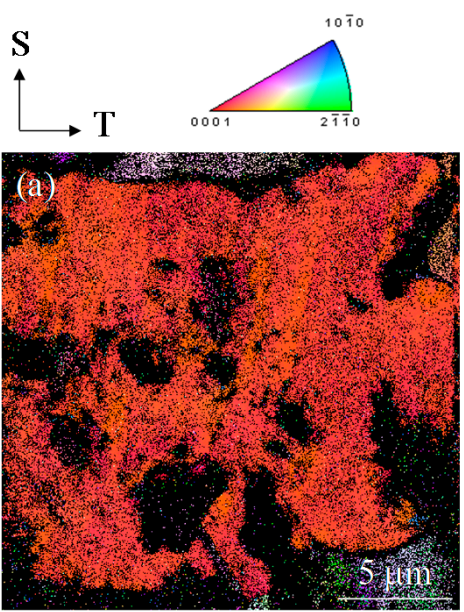
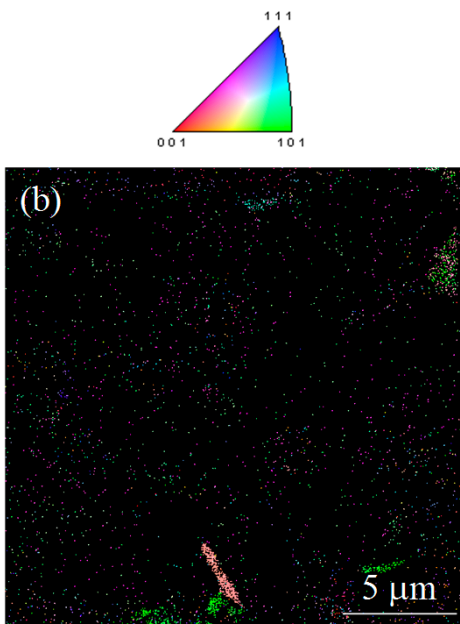
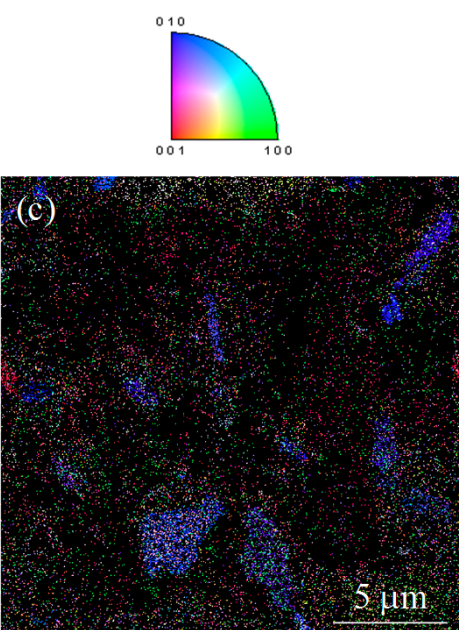

Figure 3. Inverse pole figure maps obtained by electron backscatter diffraction (EBSD) analysis for $\mathrm{TiB} / \mathrm{Ti}-3 \mathrm{Al}-2.5 \mathrm{~V}$ composites indicating the crystallographic orientation to the normal plane for (a) $-\mathrm{Ti}$, (b) $-\mathrm{Ti}$, and (c) TiB. 


\section{Results and Discussion}

\subsection{Effects of Force Ratio and TiB Orientation on Fatigue Crack Propagation}

The rates of crack growth, $\mathrm{d} a / \mathrm{d} N$ for TL and LT specimens are plotted as functions of $\Delta K$ for $R$ values of $0.1,0.5$, and 0.8 in Figure 4 . In each data series, $\Delta K_{\text {th }}$ is seen to decrease as $R$ is increased while, in contrast, $\mathrm{d} a / \mathrm{d} N$ increases. In addition, the values of $\mathrm{d} a / \mathrm{d} N$ acquired using the LT specimens (in which the TiB whiskers were perpendicular to the crack growth) are always lower than the values observed using the TL samples at the same $\Delta K$. Conversely, the $\Delta K_{\mathrm{th}}$ values of the LT series are always greater than those of the TL series. These findings indicate that fatigue crack propagation in TiB/Ti-3Al-2.5V composites under near-threshold conditions is affected by both the force ratio and the TiB orientation.

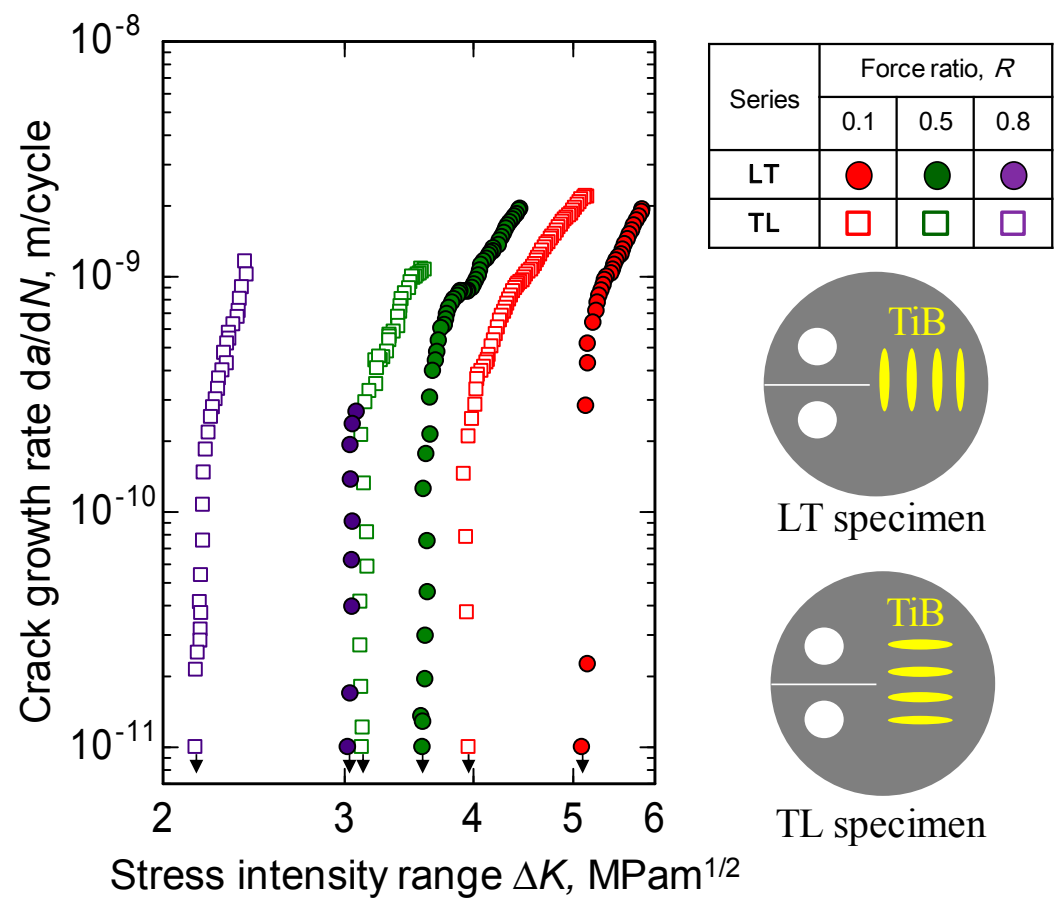

Figure 4. Relationship between crack growth rate and stress intensity range for TiB/Ti-3Al-2.5V composites having different TiB orientations.

\subsection{Crack Closure}

The effect of the force ratio in conjunction with near-threshold levels is typically ascribed to crack closure [47]. Consequently, this work examined the $\Delta K_{\text {eff }}$ values for TiB/Ti-3Al-2.5V alloys having

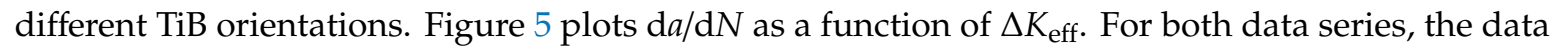
acquired at various force ratios coalesce into a single curve near the threshold at which $R$ is less than 0.5. The $\Delta K_{\text {eff,th }}$ values for the LT specimens were very similar, although the $\Delta K_{\text {eff,th }}$ at $R=0.8$ are slightly lower than those at $R=0.1$ and 0.5. Boyce and Ritchie [48] have suggested a model based on superposition for investigating the rate of fatigue crack growth in titanium alloys, taking into account cracking due to mechanical fatigue and sustained load at high force ratios. Figure 5 also revealed that the $\Delta K_{\text {eff,th }}$ at $R=0.8$ for the LT specimens was much higher than that for the TL specimens. The orientation of the TiB whiskers also modifies the sustained load cracking in this alloy.

The effects of both $\mathrm{TiB}$ orientation and force ratio on the degree of crack closure were examined by taking the ratio of $K_{\mathrm{cl}}$, the closure stress intensity factor, to $K_{\max }$, the maximum stress intensity factor, for each sample. In Figure 6 , this ratio is plotted as a function of $\Delta K_{\text {eff }}$ for both orientations at a variety of force ratios. It should be noted that $K_{\mathrm{cl}} / K_{\max }$ will be equivalent to $R$ for a specimen that does not undergo crack closure. The $K_{\mathrm{cl}} / K_{\max }$ data obtained from both types of sample were clearly not affected by $\Delta K_{\text {eff }}$ at a 0.8 force ratio, demonstrating a lack of crack closure. Conversely, in the case of $R$ values 
less than 0.5 , the ratio values obtained from the LT series increased with decreasing $\Delta K_{\text {eff }}$, while the TL series exhibited no crack closure at $R=0.5$. The LT series also produced a higher $K_{\mathrm{cl}} / K_{\max }$ than the TL series at $R$ of 0.1 and 0.5. It is therefore evident that the orientation of TiB perpendicular to the direction of crack growth promoted crack closure in the alloy, which in turn increased $K_{\text {th }}$.

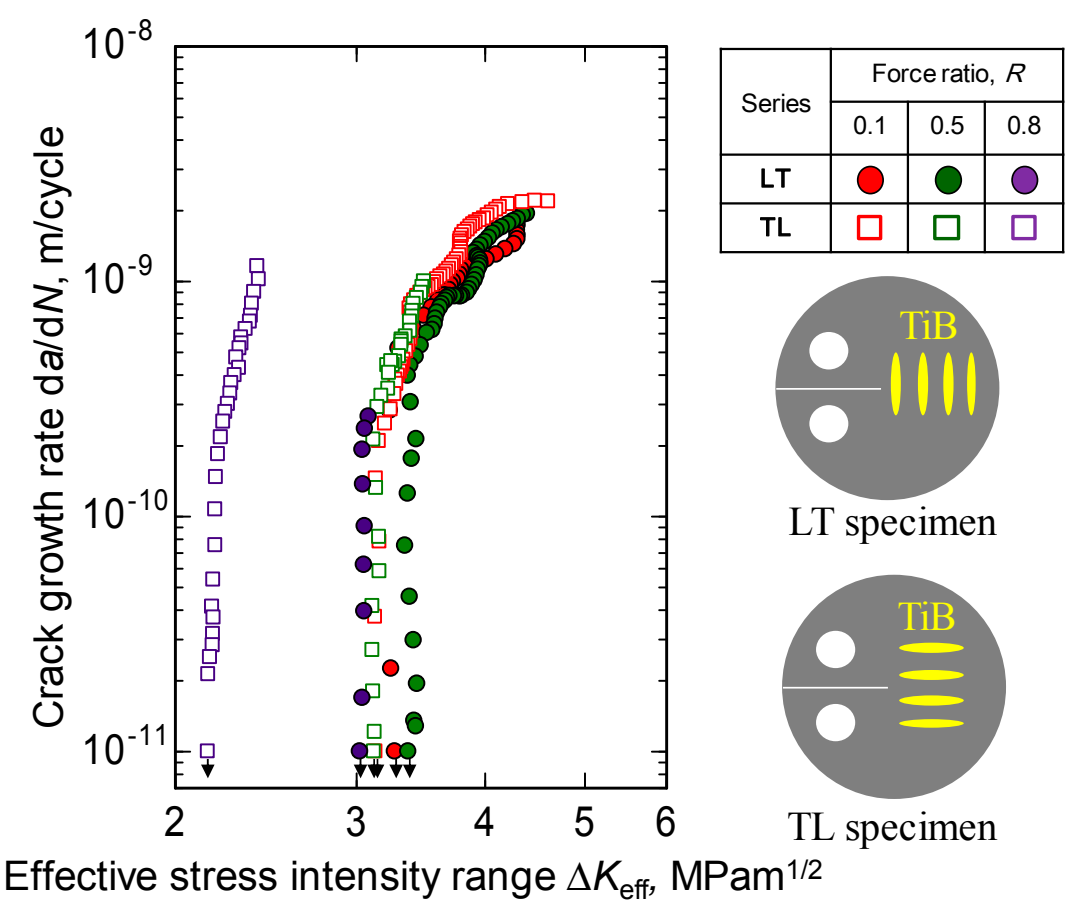

Figure 5. Relationship between crack growth rate and effective stress intensity range for TiB/Ti-3Al-2.5V composites having different TiB orientations.

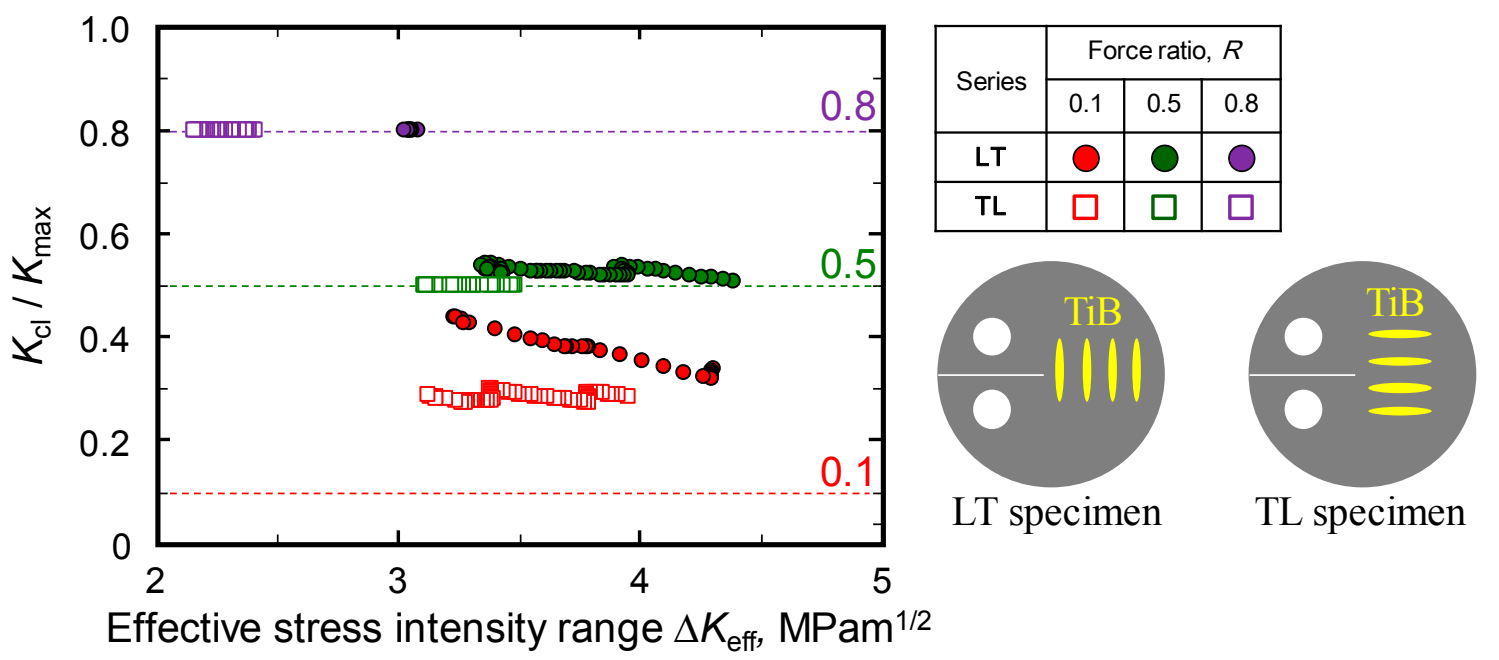

Figure 6. Relationship between $K_{\mathrm{cl}} / K_{\max }$ and effective stress intensity range for TiB/Ti-3Al-2.5V composites having different TiB orientations.

\subsection{Analyses of Crack Profiles and Fracture Surfaces}

The appearance of crack closure in association with near-threshold levels in titanium alloys is commonly ascribed to a roughness-induced process $[49,50]$. For this reason, the profiles of cracks generated in the present work were observed by SEM. Micrographs of crack profiles in both types of specimens with an $R$ of 0.1 , obtained using backscattered electron (BSE) imaging, are presented in Figure 7. The contrast in these images reflects the chemical composition of the material. Specifically, 
brighter contrast is associated with a higher atomic number. Therefore, the TiB showed up as darker than its surroundings. It is apparent that deflected and tortuous cracks were produced in the LT specimens to a greater extent than in the TL series. These results are attributed to the preferential propagation of cracks across boundaries between the TiB and the matrix in certain regions. In the case of the LT specimens, fatigue cracks were also found to propagate through the TiB.

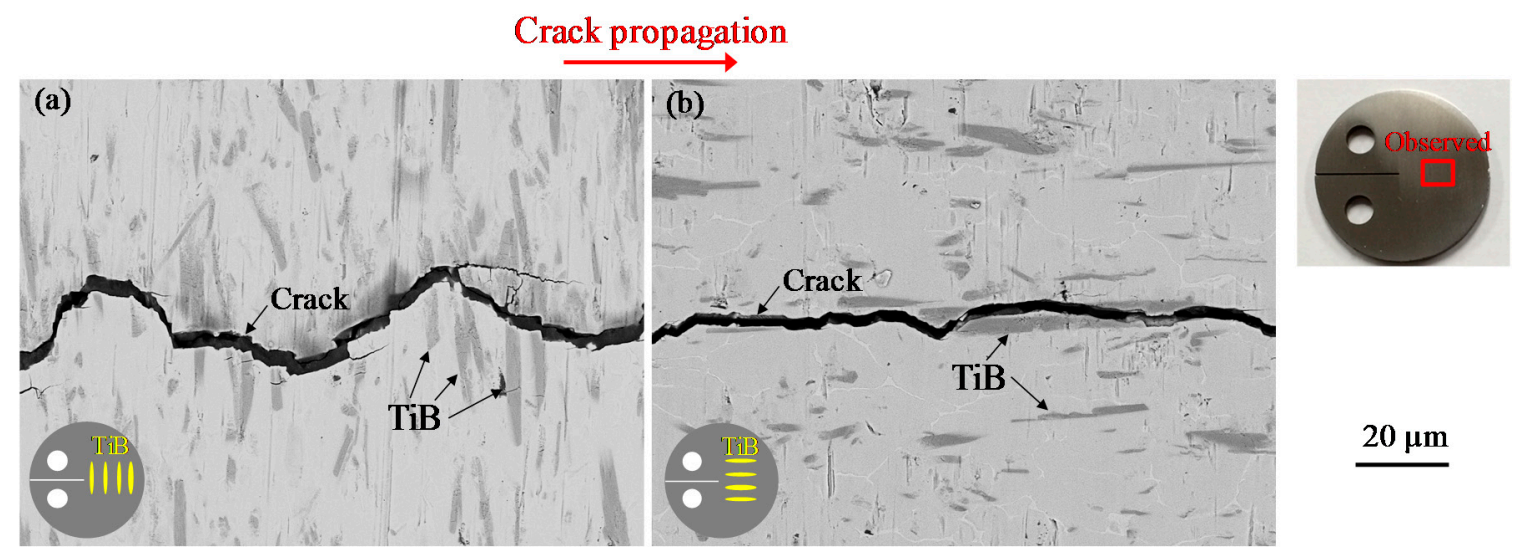

Figure 7. Backscattered electron (BSE) images obtained by SEM observations for crack profiles for (a) LT and (b) TL series after testing at $R=0.1$.

BSE images of fracture surfaces for both LT and TL specimens following testing with an $R$ of 0.1 are provided in Figure 8. In these images, it is clear that TiB was present on the fractured surfaces of both materials. $R a$, the arithmetic mean deviations for the fracture surfaces, were determined and the values were found to be greater for the LT specimen $(11.1$ versus $8.65 \mu \mathrm{m})$ as a result of the more convoluted crack path in this material. Both the present author [40] and Nalla et al. [51] have previously established that the relationship between structure and fatigue crack growth varies with the alloy microstructure. This effect increases the resistance of the alloy to the growth of fatigue cracks because of the roughness-induced crack closure. The path of cracks in a Ti-3Al-2.5V alloy reinforced with $\mathrm{TiB}$ is also affected by the orientation of the TiB. Thus, the fatigue threshold varies with the whisker orientation. For these reasons, deflected and tortuous cracks appeared in the LT specimen, which in turn enhanced the resistance to fatigue crack growth.

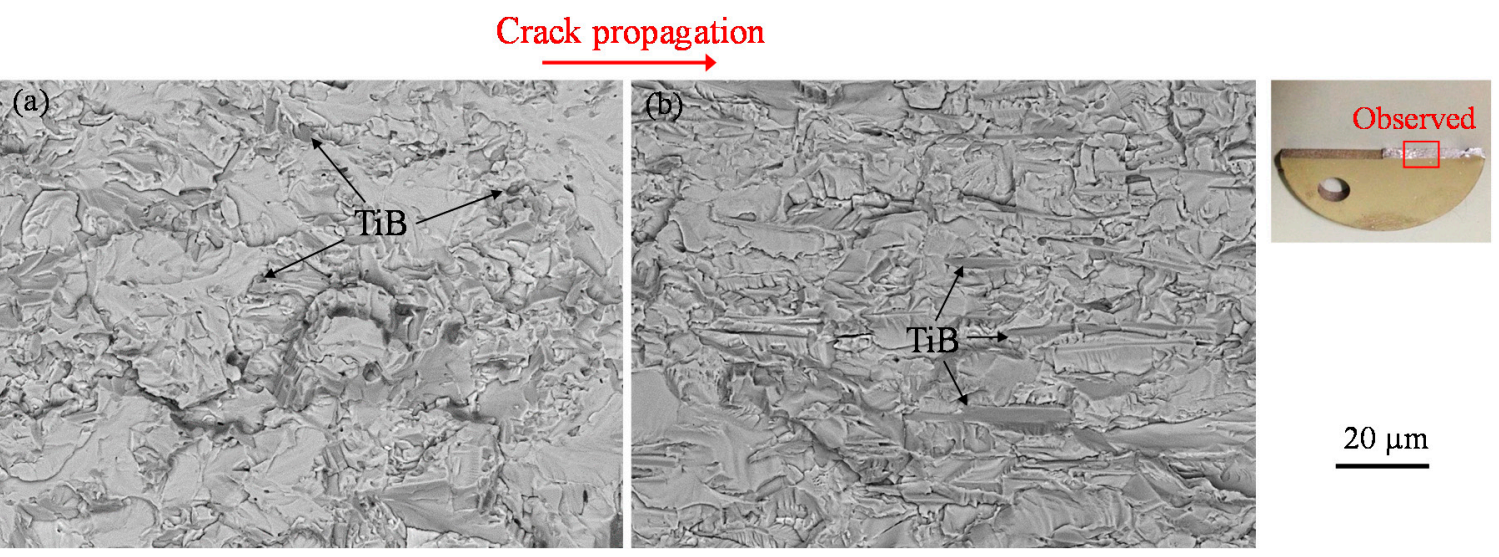

Figure 8. BSE images obtained by SEM observations for fracture surfaces for (a) LT and (b) TL series after testing at $R=0.1$.

\section{Conclusions}

This work examined the effect of the orientation of TiB whiskers on fatigue crack propagation under near-threshold conditions in TiB-reinforced Ti-3Al-2.5V. Surface analyses using both SEM and 
EPMA identified the fatigue crack propagation mechanism based on the concepts of fractography and crack closure. The primary conclusions that can be drawn from this work are as follows:

1. The orientation of TiB whiskers in a TiB-reinforced Ti-3Al-2.5V alloy determines the crack path;

2. The threshold stress intensity range values, $\Delta K_{\text {th }}$, for a Ti-3Al-2.5V alloy incorporating TiB whiskers oriented perpendicular to the direction of crack growth are greater than that obtained in the case that the orientation is parallel. This effect can be explained by the increase in the degree of the roughness-induced crack closure resulting from the perpendicular $\mathrm{TiB}$, because the deflected and tortuous cracks appear in a Ti-3Al-2.5V alloy reinforced with TiB;

3. The effective threshold stress intensity range values, $\Delta K_{\text {eff,th }}$, determined for the Ti-3Al-2.5V alloy are unaffected by the TiB orientation when the force ratio value is less than 0.5 .

Author Contributions: Conceptualization, S.K.; validation, S.K. and Y.N.; formal analysis, S.T.; investigation, T.K.; resources, T.K.; data curation, S.K.; writing—original draft preparation, S.K.; writing-review and editing, Y.N. and H.K.; visualization, S.K.; supervision, Y.N.; project administration, S.G.

Funding: This research received no external funding.

Acknowledgments: The authors would like to acknowledge Hideyuki Hirai, from Shizuoka University, for support on the EPMA and EBSD analyses of specimens.

Conflicts of Interest: The authors declare no conflict of interest.

\section{References}

1. Kurashina, Y.; Edura, A.; Murakami, R.; Mizutani, M.; Komotori, J. Effect of hydroxy groups and microtopography generated by a nanosecond-pulsed laser on pure Ti surfaces. J. Mater. Sci. Mater. Med. 2019, 30, 57-65. [CrossRef] [PubMed]

2. Ijiri, M.; Takemoto, Y. Phase transformation behavior of Ti-10Mo-7Al alloy with heat treatment. J. Jpn. Inst. Met. Mater. 2015, 79, 468-473. [CrossRef]

3. Ijiri, M.; Tomita, Y.; Ishikawa, T.; Takemoto, Y. Phase transformation behavior of Ti-35Nb-7Al alloy with tempering. J. Jpn. Inst. Met. Mater. 2016, 80, 547-552. [CrossRef]

4. Ijiri, M.; Okumura, A.; Ishikawa, T.; Kadowaki, K.; Takemoto, Y. Microstructure of Ti-4Fe-7Al alloy quenched in a salt bath after solution treatment. J. Jpn. Inst. Met. Mater. 2016, 80, 691-696. [CrossRef]

5. Ijiri, M.; Tomita, Y.; Ishikawa, T.; Kadowaki, K.; Takemoto, Y. Influence of Nb content of Ti-xNb-7Al alloys on $\beta \rightarrow \alpha^{\prime \prime}$ transformation with tempering. J. Jpn. Inst. Met. Mater. 2017, 81, 345-351. [CrossRef]

6. Fujii, T.; Tohgo, K.; Isono, H.; Shimamura, Y. Fabrication of a PSZ-Ti functionally graded material by spark plasma sintering and its fracture toughness. Mater. Sci. Eng. A 2017, 682, 656-663. [CrossRef]

7. Kikuchi, S.; Katahira, K.; Komotori, J. Formation of titanium/zirconia based biomaterials fabricated by spark plasma sintering. J. Jpn. Inst. Met. Mater. 2018, 82, 341-348. [CrossRef]

8. Kikuchi, S.; Akebono, H.; Ueno, A.; Ameyama, K. Formation of commercially pure titanium with a bimodal nitrogen diffusion phase using plasma nitriding and spark plasma sintering. Powder Technol. 2018, 330, 349-356. [CrossRef]

9. Takesue, S.; Kikuchi, S.; Akebono, H.; Misaka, Y.; Komotori, J. Effect of pre-treatment with fine particle peening on surface properties and wear resistance of gas blow induction heating nitrided titanium alloy. Surf. Coat. Technol. 2019, 359, 476-484. [CrossRef]

10. Takesuke, S.; Kikuchi, S.; Akebono, H.; Komotori, J.; Fukazawa, K.; Misaka, Y. Effects of gas blow velocity on the surface properties of Ti-6Al-4V alloy treated by gas blow IH nitriding. Mater. Trans. 2017, 58, 1155-1160. [CrossRef]

11. Kikuchi, S.; Yoshida, S.; Ueno, A. Improvement of fatigue properties of Ti-6Al-4V alloy under four-point bending by low temperature nitriding. Int. J. Fatigue 2019, 120, 134-140. [CrossRef]

12. Terada, D.; Inoue, S.; Tsuji, N. Microstructure and mechanical properties of commercial purity titanium severely deformed by ARB process. J. Mater. Sci. 2007, 42, 1673-1681. [CrossRef]

13. Kikuchi, S.; Hayami, Y.; Ishiguri, T.; Guennec, B.; Ueno, A.; Ota, M.; Ameyama, K. Effect of bimodal grain size distribution on fatigue properties of Ti-6Al-4V alloy with harmonic structure under four-point bending. Mater. Sci. Eng. A 2017, 687, 269-275. [CrossRef] 
14. Nukui, Y.; Kubozono, H.; Kikuchi, S.; Nakai, Y.; Ueno, A.; Kawabata, M.O.; Ameyama, K. Fractographic analysis of fatigue crack initiation and propagation in $\mathrm{CP}$ titanium with a bimodal harmonic structure. Mater. Sci. Eng. A 2018, 716, 228-234. [CrossRef]

15. Koga, G.Y.; Otani, L.B.; Silva, A.M.B.; Roche, V.; Nogueira, R.P.; Jorge, A.M., Jr.; Bolfarini, C.; Kiminami, C.S.; Botta, W.J. Characterization and corrosion resistance of boron-containing-austenitic stainless steels produced by rapid solidification techniques. Materials 2018, 11, 2189. [CrossRef]

16. Zhang, S.; Song, J.; Liao, H.; Liu, Y.; Zhang, G.; Ma, S.; Tang, A.; Atrens, A.; Pan, F. Effect of boron on the grain refinement and mechanical properties of as-cast Mg alloy AM50. Materials 2019, 12, 1100. [CrossRef]

17. Hernandez-Rodriguez, M.A.L.; Mercado-Solis, R.D.; Presbítero, G.; Lozano, D.E.; Martinez-Cazares, G.M.; Bedolla-Gil, Y. Influence of boron additions and heat treatments on the fatigue resistance of CoCrMo alloys. Materials 2019, 12, 1076. [CrossRef]

18. Bazhin, P.M.; Stolin, A.M.; Konstantinov, A.S.; Kostitsyna, E.V.; Ignatov, A.S. Ceramic Ti-B composites synthesized by combustion followed by high-temperature deformation. Materials 2016, 9, 1027. [CrossRef]

19. Sun, Y.; Zhang, J.; Luo, G.; Shen, Q.; Zhang, L. Microstructure and mechanical behaviors of titanium matrix composites containing in situ whiskers synthesized via plasma activated sintering. Materials 2018, 11, 544. [CrossRef]

20. Kurita, H.; Suzuki, S.; Kikuchi, S.; Yodoshi, N.; Gourdet, S.; Narita, F. Strengthening mechanism of two-dimensional randomly oriented titanium boride whisker-reinforced Ti-6Al-4V alloy matrix composites. Materials 2019, 12, 2401. [CrossRef]

21. Kurita, H.; Sakayanagi, K.; Kikuchi, S.; Yodoshi, N.; Gourdet, S.; Narita, F. Crack initiation behavior of titanium boride whisker reinforced titanium matrix composites during small punch test. Mater. Des. Process. Commun. 2019, 1, e80.

22. Wang, S.; Huang, L.; Zhang, R.; Liu, B.; Cui, X.; Geng, L.; Peng, H.X. Enhancing ductility of titanium matrix composites by multimodal $\alpha$-grains. Scr. Mater. 2019, 170, 161-165. [CrossRef]

23. Chen, W.; Boehlert, C.J.; Payzant, E.A.; Howe, J.Y. The effect of processing on the $455^{\circ} \mathrm{C}$ tensile and fatigue behavior of boron-modified Ti-6Al-4V. Int. J. Fatigue 2010, 32, 627-638. [CrossRef]

24. Chen, W.; Boehlert. The elevated-temperature fatigue behavior of boron-modified Ti-6Al-4V(wt.\%) castings. Mater. Sci. Eng A 2008, 494, 132-138. [CrossRef]

25. Chandran, K.S.R.; Panda, K.B.; Sahay, S.S. TiB ${ }_{\mathrm{W}}$-reinforced Ti composites: Processing, properties, application prospects, and research needs. JOM 2004, 56, 42-48. [CrossRef]

26. Morsi, K.; Patel, V.V. Processing and properties of titanium-titanium boride (TiBw) matrix composites (a review). J. Mater. Sci. 2007, 42, 2037-2047. [CrossRef]

27. Sen, I.; Tamirisakanadala, S.; Miracle, D.B.; Ramanmurty, U. Microstructural effects on the mechanical behavior of B-modified Ti-6Al-4V alloys. Acta Mater. 2007, 55, 4983-4993. [CrossRef]

28. Gorsse, S.; Miracle, D.B. Mechanical properties of Ti-6Al-4VTiB composites with randomly oriented and aligned TiB reinforcements. Acta Mater. 2013, 51, 2427-2442. [CrossRef]

29. Arévalo, C.; Montealegre-Melendez, I.; Pérez-Soriano, E.M.; Ariza, E.; Kitzmantel, M.; Neubauer, E. Study of the influence of $\mathrm{TiB}$ content and temperature in the properties of in situ titanium matrix composites. Metals 2017, 7, 457. [CrossRef]

30. Wang, B.; Huang, L.J.; Hu, H.T.; Liu, B.X.; Geng, L. Superior tensile strength and microstructure evolution of TiB whisker reinforced Ti60 composites with network architecture after $\beta$ extrusion. Mater. Charact. 2015, 103, 140-149. [CrossRef]

31. Hyman, M.E.; McCullough, C.; Valencia, J.J.; Levi, C.G.; Mehrabian, R. Microstructure evolution in TiAl alloys with B additions: Conventional solidification. Metall. Trans. A 1989, 20, 1847-1859. [CrossRef]

32. Li, D.X.; Ping, D.H.; Lu, Y.X.; Ye, H.Q. Characterization of the microstructure in TiB-whisker reinforced Ti alloy matrix composite. Mater. Lett. 1993, 16, 322-326. [CrossRef]

33. Feng, H.; Zhou, Y.; Jia, D.; Meng, Q.; Rao, J. Growth mechanism of in situ TiB whiskers in spark plasma sintered TiB-Ti metal matrix composites. Cryst. Growth Des. 2006, 6, 1626-1630. [CrossRef]

34. Feng, H.; Zhou, Y.; Jia, D.; Meng, Q. Microstructural Characterization of spark plasma sintered in situ TiB reinforced Ti matrix composite by EBSD and TEM. Mater. Trans. 2005, 46, 575-580. [CrossRef]

35. Schun, C.; Dunand, D.C. Whisker alignment of Ti-6Al-4V/TiB composites during deformation by transformation superplasticity. Int. J. Plast. 2001, 17, 317-340. 
36. Ropars, L.; Dehmas, M.; Gautier, E.; Tricker, D.; Schuster, D.; Gourdet, S. Effect of processing route on microstructure and mechanical properties of a Ti-3Al-2.5V/TiB composite. In Proceedings of the THERMEC'2018, Paris, France, 9-13 July 2018.

37. Ropars, L.; Dehmas, M.; Gourdet, S.; Tricker, D.; Aeby-Gautier, E. Kinetics of phase transformations in Ti-TiB composites characterized using high energy X-ray diffraction. In Proceedings of the 19th International Conference on Composite Materials, Montreal, QC, Canada, 28 July-2 August 2013.

38. Ropars, L.; Jonathan, S.; Tnaguy, B.; Gourdet, S. Characterisation of a ductile Ti-3Al-2.5V/TiBp composite produced via mechanical alloying. In Proceedings of the 12th World Conference on Titanium, Beijing, China, 19-24 June 2011; Volume 2, pp. 1402-1406.

39. Kikuchi, S.; Imai, T.; Kubozono, H.; Nakai, Y.; Ueno, A.; Ameyama, K. Evaluation of near-threshold fatigue crack propagation in Ti-6Al-4V alloy with harmonic structure created by mechanical milling and spark plasma sintering. Frat. Integrita Strutt. 2015, 34, 261-270. [CrossRef]

40. Kikuchi, S.; Imai, T.; Kubozono, H.; Nakai, Y.; Ota, M.; Ueno, A.; Ameyama, K. Effect of harmonic structure design with bimodal grain size distribution on near-threshold fatigue crack propagation in Ti-6Al-4V alloy. Int. J. Fatigue 2016, 92, 616-622. [CrossRef]

41. Kikuchi, S.; Mori, T.; Kubozono, H.; Nakai, Y.; Kawabata, M.O.; Ameyama, K. Evaluation of near-threshold fatigue crack propagation in harmonic-structured CP Titanium with a bimodal grain size distribution. Eng. Fract. Mech. 2017, 181, 77-86. [CrossRef]

42. Kikuchi, S.; Kubozono, H.; Nukui, Y.; Nakai, Y.; Ueno, A.; Kawabata, M.O.; Ameyama, K. Statistical fatigue properties and small fatigue crack propagation in bimodal harmonic structured Ti-6Al-4V alloy under four-point bending. Mater. Sci. Eng. A 2018, 711, 29-36. [CrossRef]

43. Kikuchi, S.; Nakatsuka, Y.; Nakai, Y.; Nakatani, M.; Kawabata, M.O.; Ameyama, K. Evaluation of fatigue properties under four-point bending and fatigue crack propagation in austenitic stainless steel with a bimodal harmonic structure. Frat. Integrita Strutt. 2019, 48, 545-553. [CrossRef]

44. Kikuchi, S.; Nukui, Y.; Nakatsuka, Y.; Nakai, Y.; Nakatani, M.; Kawabata, M.O.; Ameyama, K. Effect of bimodal harmonic structure on fatigue properties of austenitic stainless steel under axial loading. Int. J. Fatigue 2019, 127, 222-228. [CrossRef]

45. Zhou, G.; Ma, H.; Zhang, Z.; Sun, J.; Wang, X.; Zeng, P.; Zheng, R.; Chen, X.; Ameyama, K. Fatigue crack growth behavior in a harmonic structure designed austenitic stainless steel. Mater. Sci. Eng. A 2019, 758, 121-129. [CrossRef]

46. Kikukawa, M.; Jono, M.; Tanaka, K.; Takatani, M. Measurement of fatigue crack propagation and crack closure at low stress intensity level by unloading elastic compliance method. J. Soc. Mater. Sci. Jpn. 1976, 25, 899-903. [CrossRef]

47. Nakai, Y.; Tanaka, K. The effects of stress ratio and grain size on near-threshold fatigue crack propagation in low-carbon steel. Eng. Fract. Mech. 1981, 15, 291-302. [CrossRef]

48. Boyce, B.L.; Ritchie, R.O. Effect of load ratio and maximum stress intensity on the fatigue threshold in Ti-6Al-4V. Eng. Fract. Mech. 2001, 68, 129-147. [CrossRef]

49. Ogawa, T.; Tokaji, K.; Ohya, K. The effect of microstructure and fracture surface roughness on fatigue crack propagation in a Ti-6Al-4V alloy. Fatigue Fract. Eng. Mater. Struct. 1993, 16, 973-982. [CrossRef]

50. Sadananda, K.; Vasudevan, A.K. Fatigue crack growth behavior of titanium alloys. Int. J. Fatigue 2005, 27, 1255-1266. [CrossRef]

51. Nalla, R.K.; Boyce, B.L.; Campbell, J.P.; Peters, J.O.; Ritchie, R.O. Influence of microstructure on high-cycle fatigue of Ti-6Al-4V: Bimodal vs. lamellar structures. Metall. Mater. Trans. A 2002, 33, 899-918. [CrossRef]

(C) 2019 by the authors. Licensee MDPI, Basel, Switzerland. This article is an open access article distributed under the terms and conditions of the Creative Commons Attribution (CC BY) license (http://creativecommons.org/licenses/by/4.0/). 